\title{
Direct replication of micro-nanostructures in the fabrication of superhydrophobic silicone rubber surfaces by compression molding
}

\author{
K. Maghsoudi*, G. Momen, R. Jafari, M. Farzaneh \\ Department of Applied Sciences, University of Quebec in Chicoutimi (UQAC) \\ 555, boul. de l'Université, Chicoutimi, Québec, G7H 2B1, Canada \\ *E-mail: Khosrow.maghsoudil@uqac.ca
}

\begin{abstract}
We describe a simple method for fabricating superhydrophobic high temperature vulcanized (HTV) silicone rubber surfaces by direct replication using a compression molding system. The resulting rubber samples possessed micro-nanostructures on the surface. This micro- and nanoscale roughness produced a water contact angle of $>160^{\circ}$ and a contact angle hysteresis of $<3^{\circ}$. The roughness patterns on chemically etched aluminum surfaces, which served as templates, were successfully replicated on the rubber surfaces. An antistiction coating applied to the template surface ensured that the rubber was completely removed during demolding and that the replicated micro-nanostructures on the silicone surface were preserved. Surface roughness of the aluminum templates was optimized at $\mathrm{HCl}$ concentrations of $15 \mathrm{wt} . \%$, with a lower roughness value observed at acid concentrations above and below this value. The developed HTV silicone rubber surfaces also demonstrated a freezing delay and a self-cleaning capacity.
\end{abstract}

\section{Keywords}

Superhydrophobicity; Silicone rubber; Micro-nanostructures; Direct replication; Self-cleaning properties; Compression molding

\section{Introduction}

Due to its hydrophobic properties, silicone rubber has attracted much attention for application as high-voltage outdoor insulation [1]. Silicone rubber used in high-voltage outdoor insulation can be divided into three main subcategories: high temperature vulcanized (HTV) silicon rubber, room temperature vulcanized (RTV) silicone rubber and liquid silicone rubber (LSR). HTV rubber cured at high temperature and pressure and catalyzed with peroxide or a noble metal, such 
as platinum, possesses an inherent hydrophobicity as well as superior electrical and mechanical properties [2,3]. Given that the accumulation of ice and pollution is responsible for numerous electrical and mechanical issues involving insulators exposed to these harsh environmental conditions, outdoor insulators should ideally have superhydrophobic and self-cleaning properties $[2,4]$.

Silicone rubber, due to its hydrophobic nature, causes water droplets to form on its surface rather than allowing water to immediately flow over the surface or to form a continuous water film [5]. The water contact angle (WCA) of its smooth surface is $<120^{\circ}$ [6-8]. However, adding surface roughness can increase the WCA without altering surface chemistry. Superhydrophobic surfaces having a WCA $>150^{\circ}$ and a contact angle hysteresis $(\mathrm{CAH})<10^{\circ}$ can be created through a combination of low surface energy materials and a micro- and nanostructured surface topography [9, 10]. When water droplets roll off a superhydrophobic surface, they also carry away hydrophilic contaminants adhered to the surface [11]. Due to surface tension, the adhesion of a contaminant particle to a water droplet is stronger than the particles' adhesion to the solid surface. Thus, superhydrophobic surfaces can be considered as self-cleaning surfaces [4].

Surfaces with micro-nanostructures have been used for a range of applications including antireflection coatings, bioinspired non-reflective coatings, antipollution and self-cleaning surfaces, cell culturing and differentiation, microlenses, dry adhesion surfaces and superhydrophobic surfaces [12]. Many methods have been used to create such surfaces including self-assembly, layer-by-layer methods, plasma treatments, chemical vapor deposition, sol-gel methods, lithography, spray coating, dip coating, electrostatic spinning and electrochemical deposition $[9,13]$. There are several problems and challenges associated with the use of these methods including complex engineering procedures, long fabrication times, expensive facilities, environmental concerns and less than optimal robustness when the methods are applied to realworld settings $[9,14]$. Consequently, a simple approach, such as the use of templates to create replicates having surficial micro-nanostructures, is preferable for reducing fabrication time and costs, applying to a wide range of materials, being easy to use and being reproducible. Moreover, using templates as replica to create micro-nanostructured surfaces favors mass production and is a method that is widely acceptable to industry. In addition, direct replication creates a 
superhydrophobic surface out of the bulk material, while the aforementioned techniques create an additional layer on the parent material.

Use of templates or direct replication has been widely used for making micro-nanostructures on the surface of polymeric materials $[14,15]$. A variety of materials can be used to fabricate such templates or inserts: nickel, steel, BMG (bulk metallic glass) and aluminum [12]. Considering the ease of creating patterns through mechanical machining, chemical etching and electroforming on metals, they represent materials that offer a high potential as templates. Moreover, there are numerous ways to create an aluminum surface having micro and/or nanostructures including chemical etching [16, 17], anodization [18-21], boiling water [22, 23], plasma treatment [22, 24, 25], laser ablation [26-28] and lithography [29-31]. Various solutions have been used for chemically etching aluminum surfaces. Hydrochloric acid - at various concentrations - is one of the most common chemical etchants used for this purpose [32-34].

These structured templates can then be used in a wide range of polymer processing techniques, such as injection molding [12, 35-37], injection compression molding [38-40], compression molding [41-43] and hot embossing [44-48], to produce micro-nanostructured polymer surfaces via replication. Liu et al. [14] produced superhydrophobic polymeric surfaces using Al and $\mathrm{Al}_{2} \mathrm{O}_{3}$ replicas obtained via the anodization technique. Weng et al. [49] achieved a superhydrophobic electro-active epoxy coating by direct replication of fresh plant leaves, while Bhagat et al. [50] fabricated superhydrophobic polycarbonates (PC) using silicon wafer templates via a hot embossing process. Through femtosecond laser ablation and a hot embossing system, Toosi et al. [51] imprinted topographical stainless steel (SS) micro-nanostructured patterns onto the surface of thermoplastic polymers that included high-density polyethylene (HDPE), polylactic acid (PLA) and medical PVC. Cao et al. [52] fabricated superhydrophobic high-density polyethylene (HDPE) surfaces via a nanoinjection molding technique using a template of porous anodic aluminum (PAA) having pore diameters of $200 \mathrm{~nm}$. Injection-molded superhydrophobic polypropylene (PP) surfaces with microstructures and hierarchical anisotropic micro-nanostructures (dual structures) have also been studied [53, 54]. The fabrication of microstructured inserts, produced using a micro-working robot on aluminum foil, and micronanostructured inserts, obtained by anodizing aluminum foil, demonstrated that microstructures 
can, in some cases, produce superhydrophobic surfaces, while dual surfaces (i.e. surfaces with micro-nanostructures) always lead to a superhydrophobic surface having a CA of $>150^{\circ}$.

Most studies involving the fabrication of superhydrophobic polymeric surfaces have used thermoplastics as the matrix. Some studies have also used poly(dimethylsiloxane) (PDMS) [55, 56] and LSR [15, 57] for producing structured superhydrophobic surfaces. However, few studies have employed HTV rubber materials to create textured superhydrophobic surfaces [4], and thus there is a need for further investigation using this material.

Here, we present an efficient and simple method for fabricating micro-nanostructured rubber surfaces using a compression molding system. Compression molding is one of the most common methods for producing high volume polymer parts and components. Unlike conventional means for making superhydrophobic HTV silicone surfaces that rely mainly on coating techniques [1, 58-60], we produce a micro-nanostructured template using simple chemical etching and subsequent direct replication of micro-nanostructures on the HTV silicone during its vulcanization process. Consequently, no additional coating is required to achieve a WCA of $>160^{\circ}$. Replication quality depends greatly on having a well-structured and durable template that can be used repeatedly without considerable loss of roughness and having a technique to detach the mold without damage to the produced surface nor to the original template.

\section{Materials and methods}

All samples were made of HTV silicone rubber compound as received. The direct replication method was used to fabricate samples marked by micro-nanostructures (Fig. 1). 


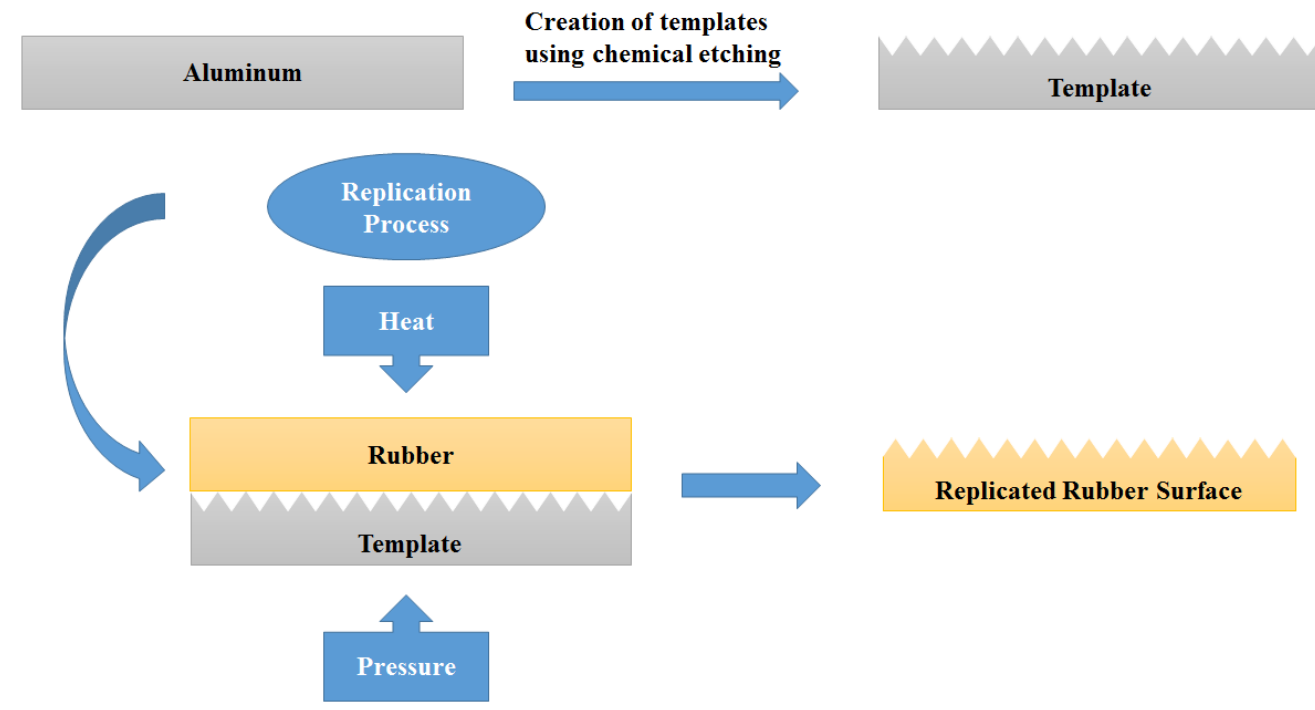

Fig. 1. Schema of the replication of micro-nanostructures on the surface of HTV silicone rubber from chemically etched aluminum templates to illustrate the replication of patterns on the template through curing under pressure and heat.

\subsection{Equipment}

A press machine (Carver Inc.) was used in the compression molding process to fabricate micronanostructured rubber surfaces. Maximum clamp capacity of the machine is 15 tons with an adjustable force from 700 to $43700 \mathrm{lbs}$. The machine has two temperature-controllable platens. Temperature range varies from ambient temperature to $350{ }^{\circ} \mathrm{C}$. A three-piece flat mold having a cavity size of $25 \times 25 \times 6.5 \mathrm{~mm}$ cast the rubber materials.

\subsection{Fabrication of templates}

A chemical etching method created micro-nanostructures on a A6061 aluminum alloy composed of Al 97.9 wt.\%, Mg 1.0 wt.\%, Si 0.60 wt.\%, Cu 0.28 wt.\% and Cr 0.20 wt.\%. The templates were cut into the desired size and ultrasonically cleaned in acetone and distilled water. They were then dried. The surfaces were chemically etched using three different hydrochloric acid concentrations (10, 15 and $20 \mathrm{wt} . \%$ ) for various etching times (1, 2, 3 and $4 \mathrm{~h}$ ). All etched templates were then ultrasonically cleaned with acetone and distilled water to remove any residual particles from the surfaces. The clean etched templates were dried in an oven at $70{ }^{\circ} \mathrm{C}$ for $1 \mathrm{~h}$. The nomenclature of samples relates to the conditions under which the samples were produced. For example, sample $\mathrm{C} 15 \mathrm{H} 2$ represents a silicone rubber sample produced using a template created immersed in $15 \mathrm{wt} . \% \mathrm{HCl}$ acid for $2 \mathrm{~h}$. 
Although the templates produced using the chemical etching method possessed micronanostructures, they did not show favorable demolding behavior. Throughout the demolding step, rubber material stuck onto the template surface, and the final product was ruined or lacked the roughness of the template. Use of a proper demolding agent could solve this problem, but this would still not guarantee a perfect demolding due to the micro-nanostructures on the surface. Moreover, post-process cleaning is required as most release agents leave contaminants on the surface [61]. Therefore, working with micro- and nano- scale structures requires more targeted strategies. Furthermore, dislodging the rubber materials entangled in the template structuresdue to the high molding pressure and the structures being cured in situ-represents a serious challenge and makes it impossible to reuse the template after the first molding cycle. Therefore, we applied an antistiction coating to make the insert surfaces impermeable against rubber materials.

Low surface energy coatings are commonly used as antistiction coatings via the self-assembled monolayer (SAM) method. Fluorocarbon- or hydrocarbon-based coating materials are the most common antistiction coatings [12]. We applied a $6 \mathrm{mM}$ solution of diluted Trichloro(1H,1H,2H,2H-perfluorooctyl)silane in methanol $\left(\mathrm{TPFS}=\mathrm{CF}_{3}\left(\mathrm{CF}_{2}\right)_{5} \mathrm{CH}_{2} \mathrm{CH}_{2} \mathrm{SiCl}_{3}\right.$, supplied by Sigma-Aldrich ${ }^{\circledR}$ ) as an antistiction coating for the aluminum template surfaces. The solution was stirred for $15 \mathrm{~min}$ before dip coating. Immersion lasted $2 \mathrm{~h}$ at a temperature of 70 ${ }^{\circ} \mathrm{C}$. After drying at $70^{\circ} \mathrm{C}$ for $1 \mathrm{~h}$, the dip-coated aluminum templates were ready to be used in the replication process. The difference between the replication qualities when using an antistiction coating is schematically illustrated in Fig. 2. Templates having an antistiction coating were not damaged during the demolding phase and the replicated rubber surface had an adequate roughness. The main advantages of the antistiction coatings were a considerable improvement in replication quality and a reduced filling of micro-nanostructures on the template by polymer materials $[62,63]$. 

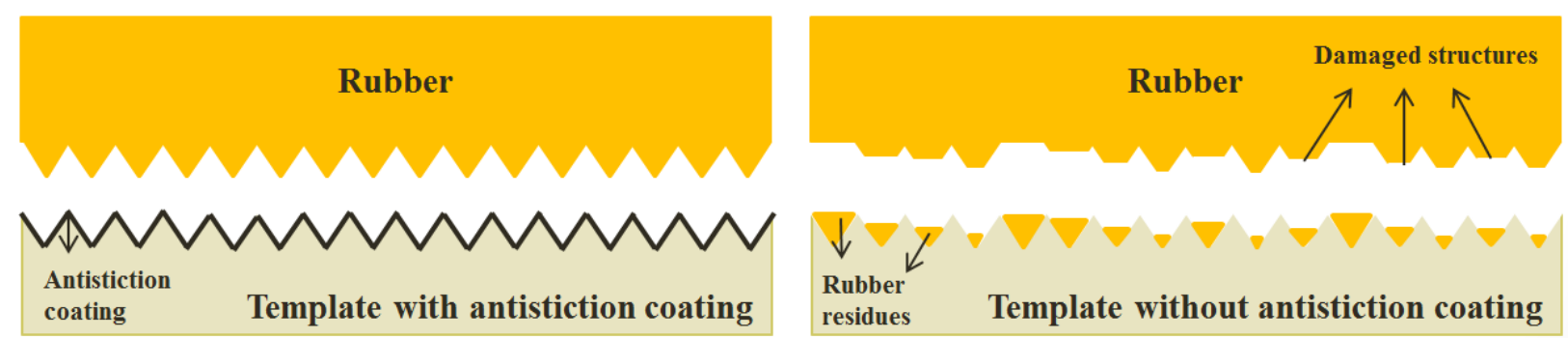

Fig. 2. Comparison of replication quality for samples with and without an antistiction coating

\subsection{Replication process}

The template was placed carefully into the cavity. The rubber compound was put into the cavity on the template; three pieces of the mold were fastened and placed on the lower platen of the press machine at an elevated temperature. According to the manufacturer guidelines, crosslinked bonds within the rubber material form at such temperature. Subsequently, the two platens were pressed closer together using a hydraulic pump until the desired pressure was reached. The platens were kept closed to let the rubber be completely cured. When the cycle was over, the platens opened and the cured rubber was demolded.

\subsection{Surface characterization}

A Kruss ${ }^{\mathrm{TM}}$ DSA100 goniometer determined WCA and CAH at $25 \pm 0.5{ }^{\circ} \mathrm{C}$. A $4 \mu \mathrm{L}$ water droplet deposited onto the sample surface permitted us to determine the WCA using the YoungLaplace approximation. The $\mathrm{CAH}$ equaled the difference of advancing and receding contact angles when the water droplet moved on the surface. To ensure accuracy and reproducibility, we conducted WCA measurements at different points on each sample; we reported the average WCA and standard deviation for each sample.

In a cold chamber, where sample stage temperatures can reach $-30^{\circ} \mathrm{C}$, we determined freezing delay using the same equipment as for contact angle measurements. Freezing delay time was defined as the time required for a water droplet on the sample surface to start freezing (freezing onset).

Fourier transform infrared spectroscopy (FTIR) analyzed the chemical functions on the surface to evaluate surface chemical composition and its contribution to wetting behavior. These analyses ran using a Cary 630 FTIR Spectrometer (Agilent, USA) in ATR (attenuated total reflection) mode to acquire the highest quality spectra in the infrared range of 400 to $4000 \mathrm{~cm}^{-1}$. 
A scanning electron microscope (JSM-6480 LV SEM manufactured by JEOL Japan) provided an observation of the micro-nanostructure morphology of the molded silicone rubber surfaces. An optical profiler (Profil3D, Filmetrics, USA) quantified surface roughness which permitted an assessment of replication quality.

We also studied the self-cleaning properties of the produced silicone surfaces using a highquality digital camera to record images. The samples were set on a substrate with an imposed tilt angle of $3^{\circ}$. Carbon black particles were selected as contaminants. We examined the selfcleaning capacity of produced samples by using a microsyringe to release droplets, having a diameter of about $3 \mathrm{~mm}$, onto the contaminant-covered surface.

\section{Results and discussion}

\subsection{Superhydrophobicity}

All silicone rubber samples having micro-nanostructures, regardless of the conditions under which they were produced, showed WCA $>160^{\circ}$ (Fig. 3). 


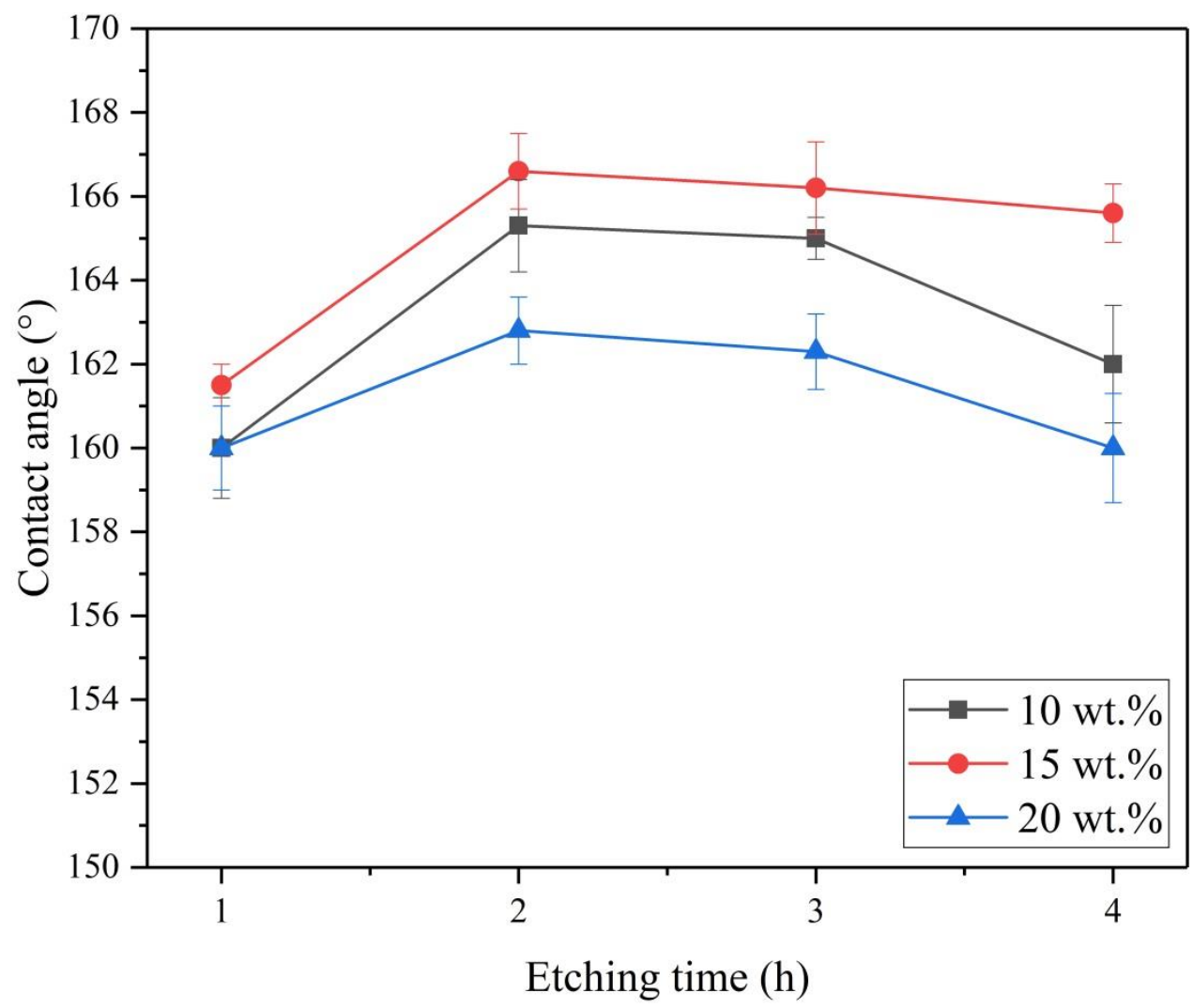

Fig.3. Contact angle of various replicated rubber surfaces produced from templates subjected to various acid concentrations $(10,15,20 \mathrm{wt} . \%)$ as a function of etching time.

As expected, the silicone rubber surface without micro-nanostructures (hereinafter referred to as pristine silicone rubber) produced a WCA of $116.0 \pm 2.0^{\circ}$. The WCA of silicone rubber surfaces having micro-nanostructures were significantly greater in comparison to the pristine silicone rubber. Water droplets on the replicated rubber surface clearly demonstrated the superhydrophobic properties of the produced samples (Fig. 4). 

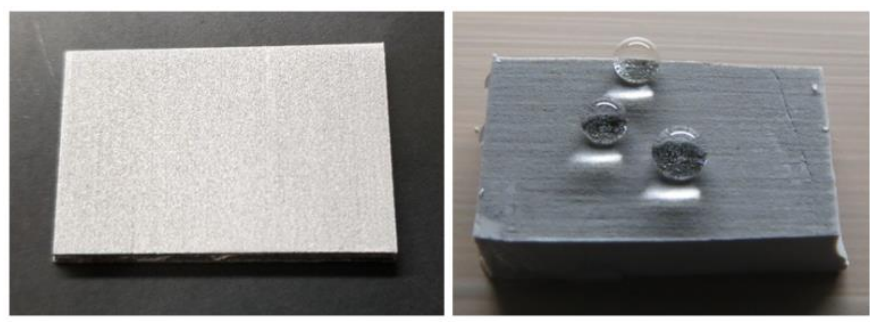

Fig. 4. Aluminum template and the replicated superhydrophobic rubber surface

\subsection{Contact angle hysteresis}

Relative to pristine HTV, CAH values for the replicated rubber samples obtained from the etched surfaces were very low (Table 1). Ultralow CAH values were obtained, however, for the C15 samples. We selected those samples having the lowest CAH and highest WCA values for further detailed study (indicated in bold in Table 1). Comparison of CAH of the pristine HTV silicone rubber and that of the $\mathrm{C} 15 \mathrm{H} 2$ sample demonstrated that the replicated patterns created a sufficient surface roughness to achieve a Cassie-Baxter state [64]. The presence of entrapped air in micro-nanostructures underneath the water droplet created a composite solid-liquid-air interface that explained this water droplet behavior [25].

Table 1. Water contact angle and contact angle hysteresis values for the pristine HTV silicone rubber surface and the replicated HTV surfaces. Samples in bold were selected for further detailed study.

\begin{tabular}{|c|c|c|}
\hline Sample & $\left.\mathbf{W C A}^{\circ}\right)$ & $\mathbf{C A H}\left({ }^{\circ}\right)$ \\
\hline Pristine HTV & $116.0 \pm 2$ & $46.5 \pm 2.4$ \\
\hline $\mathrm{C} 10 \mathrm{H} 1$ & $160 \pm 1.2$ & $1.8 \pm 0.3$ \\
\hline $\mathbf{C 1 0 H} 2$ & $\mathbf{1 6 5 . 3} \pm 1.1$ & $\mathbf{1 . 5} \pm \mathbf{0 . 2}$ \\
\hline $\mathrm{C} 10 \mathrm{H} 3$ & $165 \pm 0.5$ & $1.6 \pm 0.3$ \\
\hline $\mathrm{C} 10 \mathrm{H} 4$ & $162 \pm 1.4$ & $2 \pm 0.4$ \\
\hline $\mathrm{C} 15 \mathrm{H} 1$ & $161.5 \pm 0.5$ & $0.4 \pm 0.1$ \\
\hline $\mathbf{C 1 5 H 2}$ & $\mathbf{1 6 6 . 6} \pm 0.9$ & $\mathbf{0 . 6} \pm \mathbf{0 . 3}$ \\
\hline $\mathrm{C} 15 \mathrm{H} 3$ & $166.2 \pm 1.1$ & $0.3 \pm 0.2$ \\
\hline $\mathrm{C} 15 \mathrm{H} 4$ & $165.6 \pm 0.7$ & $0.4 \pm 0.2$ \\
\hline $\mathrm{C} 20 \mathrm{H} 1$ & $160 \pm 1$ & $1.4 \pm 0.3$ \\
\hline C20H2 & $\mathbf{1 6 2 . 8} \pm 0.8$ & $\mathbf{1 . 3} \pm \mathbf{0 . 8}$ \\
\hline $\mathrm{C} 20 \mathrm{H} 3$ & $162.3 \pm 0.9$ & $1.0 \pm 0.5$ \\
\hline
\end{tabular}




\begin{tabular}{|l|l|l|}
\hline $\mathrm{C} 20 \mathrm{H} 4$ & $160 \pm 1.3$ & $1.2 \pm 0.4$ \\
\hline
\end{tabular}

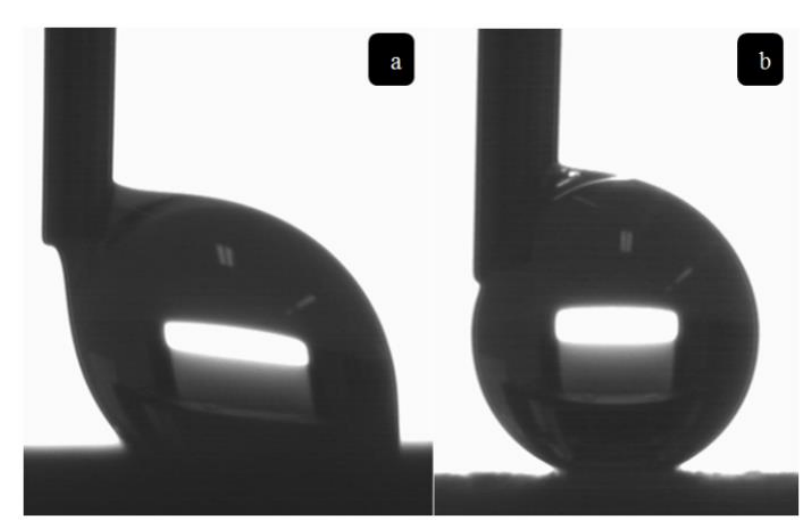

Fig. 5. Water droplet showing contact angle hysteresis of (a) pristine silicone rubber and (b) sample $\mathrm{C15H} 2$ surfaces

\subsection{Surface characterization}

SEM images testify to the creation of micro-nanostructures on the HTV silicone rubber after the replication process (Fig. 6). These micro-nanostructures were responsible for the superhydrophobic behavior.
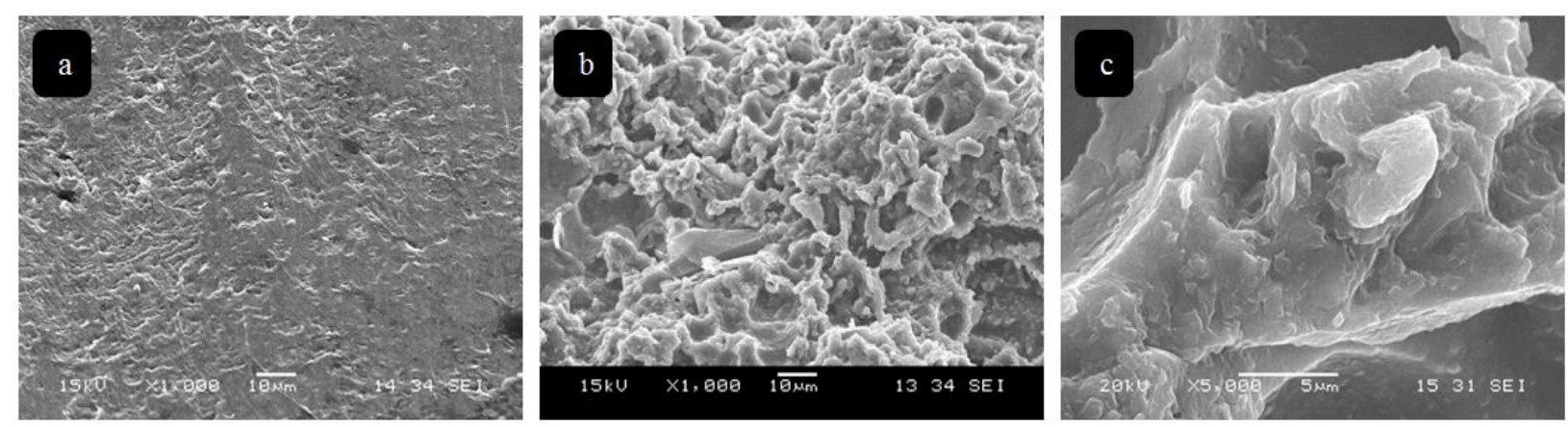

Fig. 6. SEM images of (a) pristine silicone rubber and sample $\mathrm{C} 15 \mathrm{H} 2$ at magnifications of $(\mathrm{b}) \times 1000$ and $(\mathrm{c}) \times 5000$. The images were taken with a tilt angle of $\sim 35^{\circ}$ to improve the quality of the scan imagery.

In order to study the effects of acid concentration on the produced replicates, SEM images of three replicated silicone samples from templates produced at three different acid concentrations, each immersed for $2 \mathrm{~h}(\mathrm{C} 10 \mathrm{H} 2, \mathrm{C} 15 \mathrm{H} 2$ and $\mathrm{C} 20 \mathrm{H} 2)$ were compared. Relative to the other samples, sample $\mathrm{C} 15 \mathrm{H} 2$ had a more uniform roughness across the surface (Fig. 7). These homogeneous micro-nanostructures on $\mathrm{C} 15 \mathrm{H} 2$ improved wettability properties; the largediameter depressions of sample $\mathrm{C} 10 \mathrm{H} 2$ and the fewer nanostructures on the surface of sample $\mathrm{C} 2 \mathrm{OH} 2$ reduced their respective superhydrophobicity. 

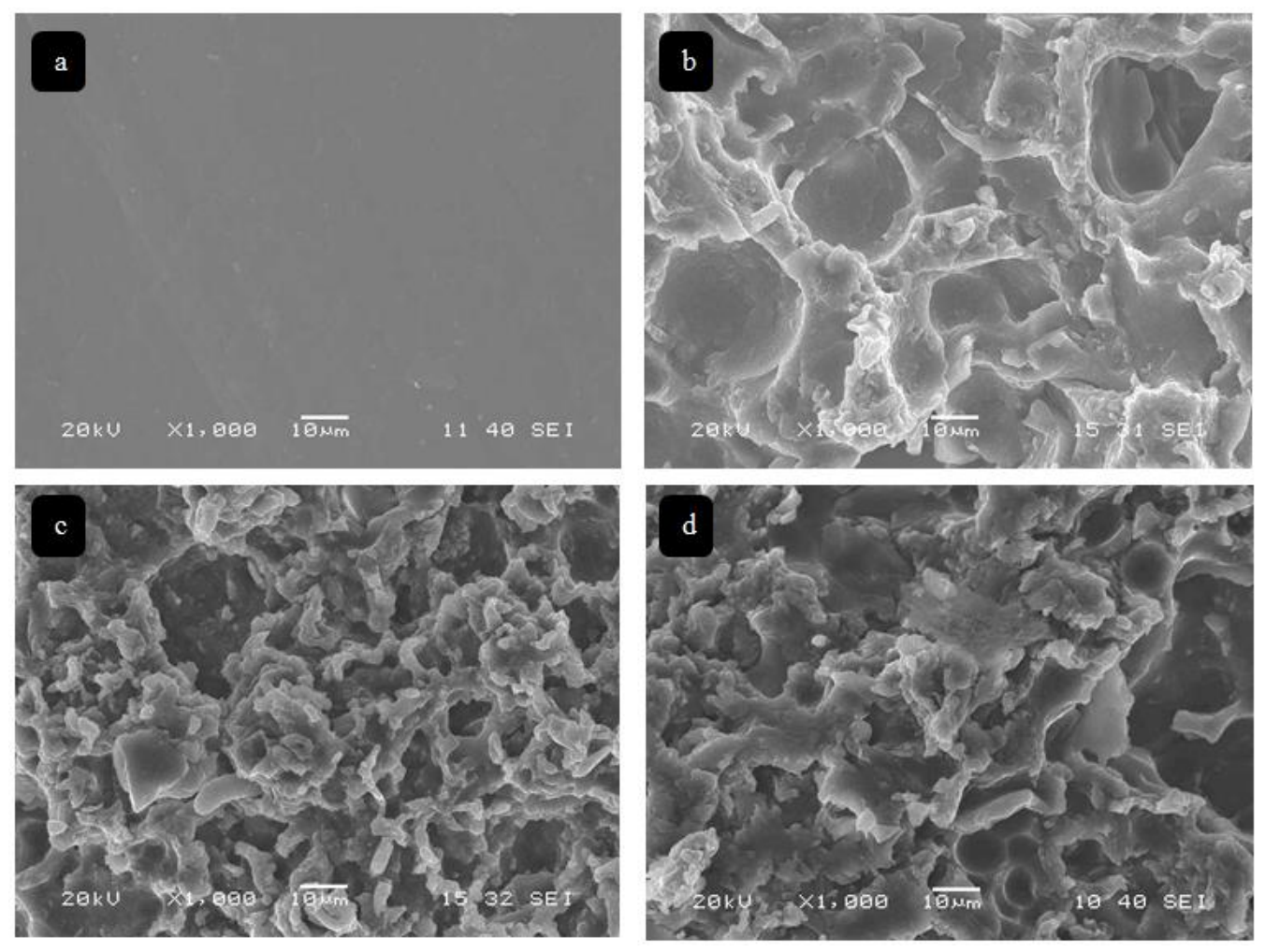

Fig. 7. SEM images of (a) pristine HTV silicone rubber surface and samples (b) $\mathrm{C10H} 2$, (c) $\mathrm{C15H} 2$ and (d) $\mathrm{C2OH} 2$. All images were taken vertically and represent the pitted morphology of the surfaces.

We selected sample $\mathrm{C} 15 \mathrm{H} 2$ to study template replication quality. SEM images of the original template and the replicated silicone rubber surfaces confirm the successful replication of the patterns on the silicone surfaces (Fig. 8). Compression molding efficiently forced materials into the roughened areas to successfully recreate the patterns on the silicone surface. These replicated patterns were almost identical to the aluminum template patterns. Obviously, protrusions on the template surface led to the creation of pitted morphology on the silicone surface, and thus depressions on the template produced protrusions on the silicone surface. 

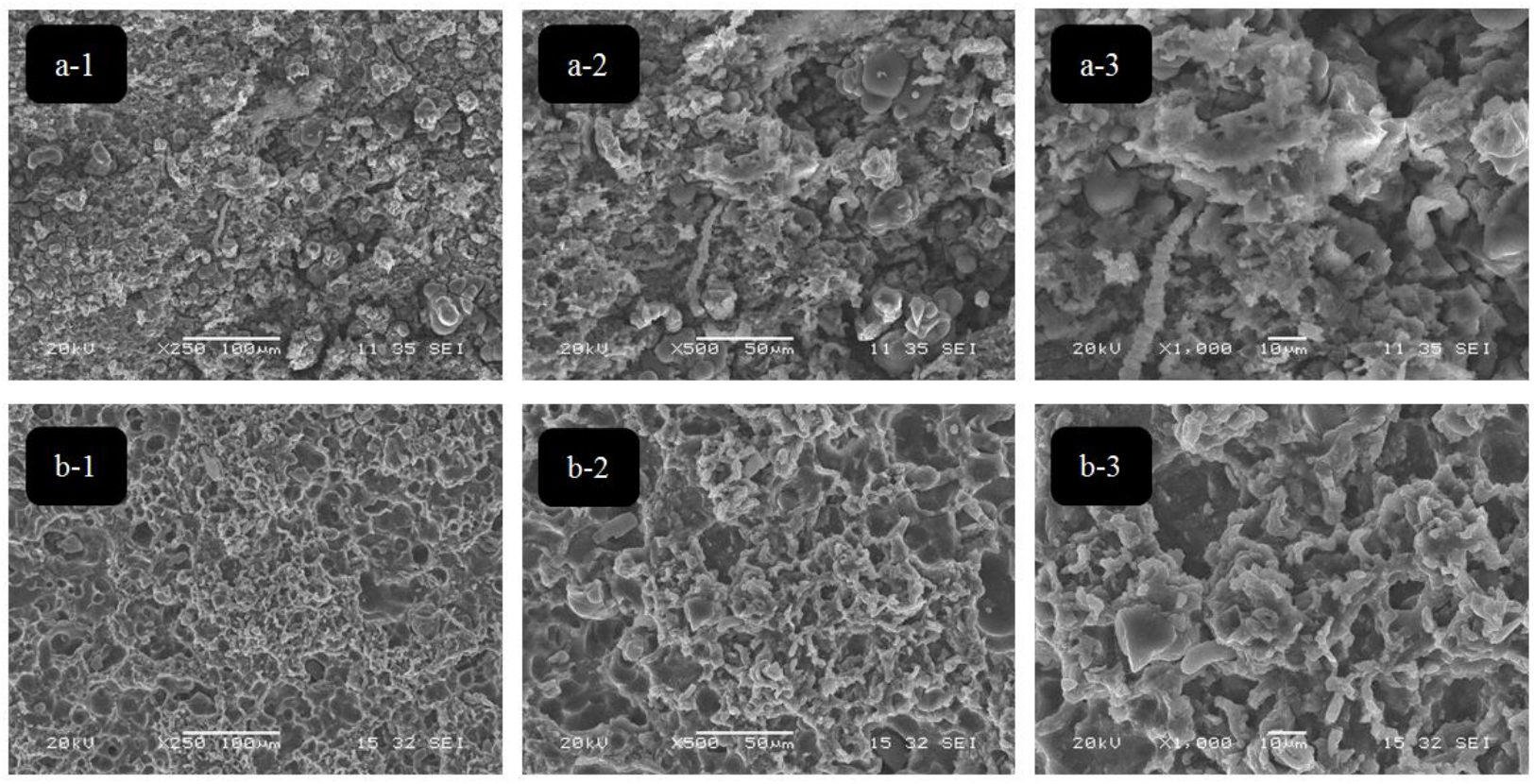

Fig. 8. SEM images of (a) aluminum template and (b) $\mathrm{C} 15 \mathrm{H} 2$ with various magnifications

As the templates were covered with an antistiction coating, we needed to ensure that the coating was not removed from the aluminum template and transferred to the silicone surface. If so, the superhydrophobic property of replicated surfaces would be attributed to the presence of the fluoric bonds produced from the antistiction coating. To assess the presence of chemical bonds on the sample surfaces, we performed FTIR analyses. FTIR spectra results for pristine HTV silicone rubber (without micro-nanostructures) and sample $\mathrm{C} 15 \mathrm{H} 2$ (with micro-nanostructures) all had absorption spectra of $\mathrm{Si}-\mathrm{O}-\mathrm{Si}, \mathrm{Si}\left(\mathrm{CH}_{3}\right)_{2}$ and $\mathrm{Si}\left(\mathrm{CH}_{3}\right)$ at approximate positions $1000-1110$ $\mathrm{cm}^{-1}, 805-855 \mathrm{~cm}^{-1}$, and $1245-1275 \mathrm{~cm}^{-1}$, respectively, attributed to silicone rubber chemical bonds and no fluorinated bonds being observed. Thus, the silicone surfaces were not altered chemically after the replication process. Consequently, the superhydrophobic behavior of silicone rubbers was only due to the creation of micro-nanostructures on the surface. 


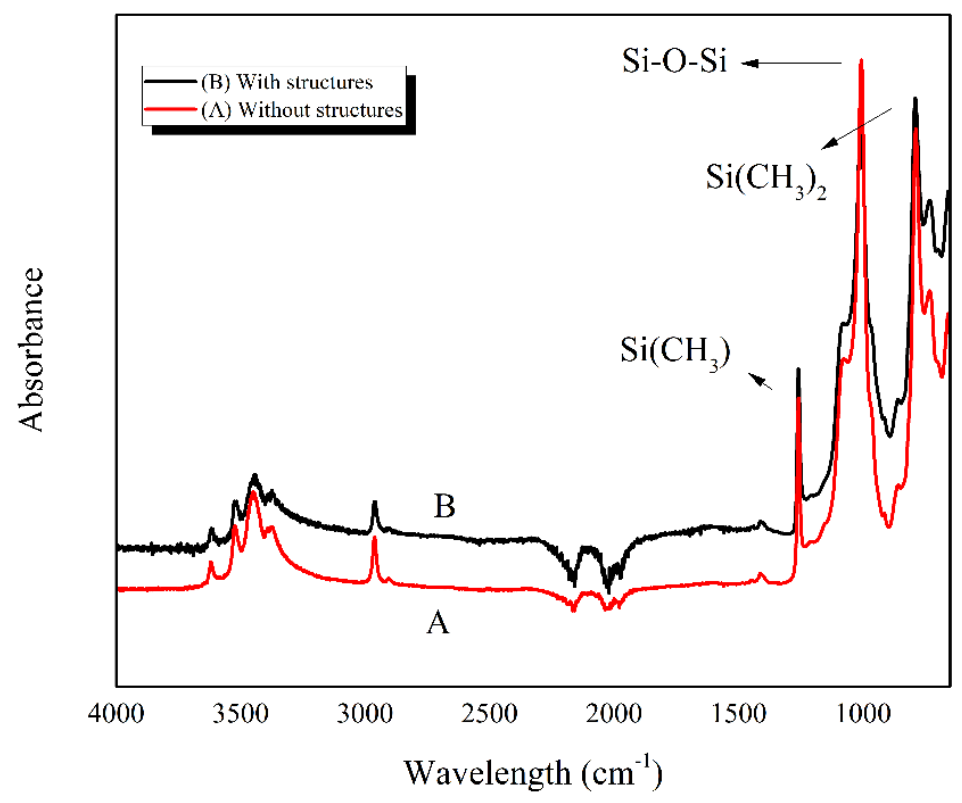

Fig. 9. FTIR spectra for HTV silicone rubber with and without structures

We applied a profilometry technique to evaluate sample roughness of a $300 \times 400 \mu \mathrm{m}$ surface. Roughness on the sample $\mathrm{C} 15 \mathrm{H} 2$ was significantly greater than that of the pristine surface after replication process (Fig. 10). The increased roughness was apparent for all three acid concentrations (Table 2).
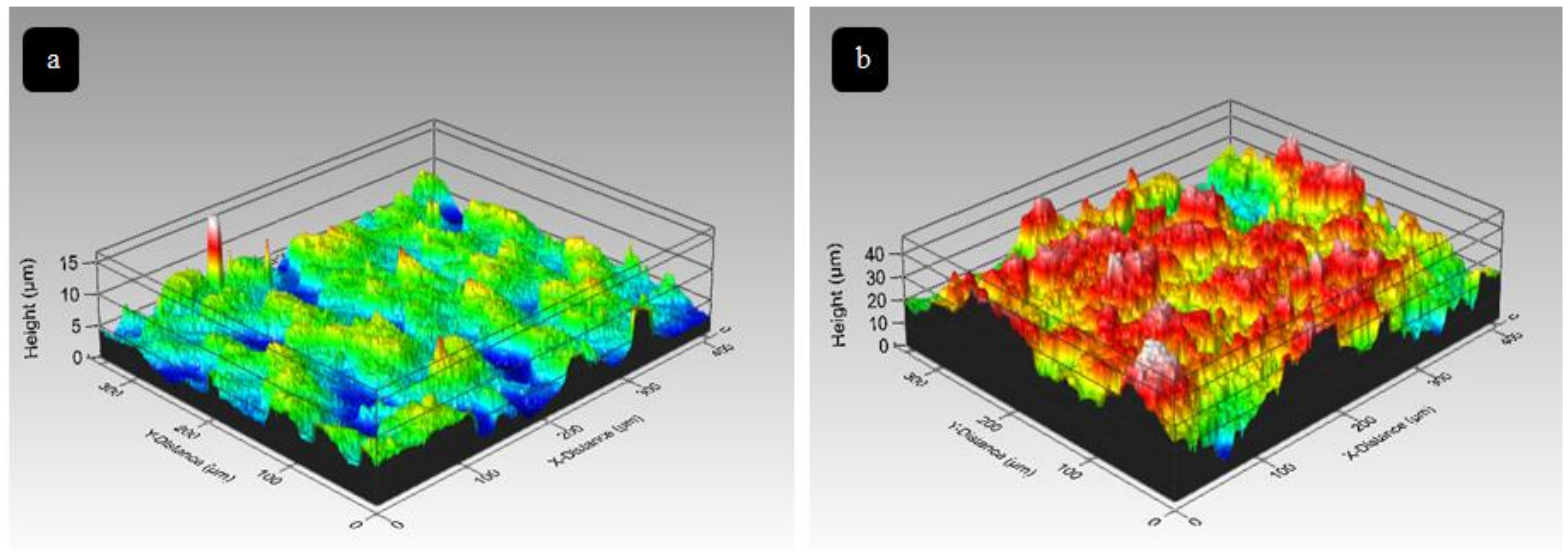

Fig. 10. Surface profiles of (a) pristine silicone rubber and (b) sample C15H2.

Table 2. Roughness values obtained from profilometry analysis.

\begin{tabular}{l|l} 
Roughness parameters & Roughness values $(\mu \mathrm{m})$
\end{tabular}




\begin{tabular}{|c|c|c|c|c|}
\hline & $\begin{array}{c}\text { Pristine silicone } \\
\text { rubber }\end{array}$ & $\mathrm{C} 10 \mathrm{H} 2$ & $\mathrm{C} 15 \mathrm{H} 2$ & $\mathrm{C} 20 \mathrm{H} 2$ \\
\hline $\mathrm{R}_{\mathrm{a}}$ (arithmetic average) & 0.79 & 4.79 & 6.49 & 4.75 \\
\hline $\mathrm{R}_{\mathrm{q}}$ (root mean squared) & 0.91 & 5.80 & 7.90 & 5.81 \\
\hline $\mathrm{R}_{\mathrm{v}}$ (maximum valley depth) & 1.65 & 11.00 & 16.07 & 11.54 \\
\hline $\mathrm{R}_{\mathrm{p}}$ (maximum peak height) & 1.95 & 11.57 & 16.71 & 11.85 \\
\hline $\mathrm{R}_{\mathrm{t}}$ (maximum height of the profile) & 3.60 & 28.61 & 40.03 & 31.25 \\
\hline
\end{tabular}

The highest roughness values were obtained for the sample $\mathrm{C} 15 \mathrm{H} 2$, a template produced using an acid concentration of $15 \mathrm{wt} . \%$ and a $2 \mathrm{~h}$ etching time. Relative to the pristine silicone surface, $\mathrm{R}_{\mathrm{a}}$ and $\mathrm{R}_{\mathrm{t}}$ roughness of sample $\mathrm{C} 15 \mathrm{H} 2$ increased $\sim 8$ and $\sim 11$ times, respectively. This testifies to the creation of a micro-nanostructured surface and the presence of micro air pockets as well.

For samples $\mathrm{C} 10 \mathrm{H} 2$ and $\mathrm{C} 20 \mathrm{H} 2$, roughness values were very similar, mirroring these samples' wettability behavior. Thus, we observed optimal chemical etching conditions for the fabrication of the highest quality micro-nanostructures. Increasing the acid concentration from $10 \mathrm{wt} \%$ to 15 wt.\% created a rougher surface due to the higher etchant concentration and reaction rate. However, when the acid concentration was increased to $20 \mathrm{wt} . \%$, a greater amount of etching actually produced a flatter surface as increased etching degraded the roughened areas and smoothed the structures.

\subsection{Freezing delay measurements and wettability behavior at supercooled temperatures}

As the behavior of produced surfaces at supercooled temperatures is important for developing icephobic and superhydrophobic surfaces that will be exposed to harsh environmental settings [65], we studied the delay in freezing onset, i.e. the initiation of water droplet freezing on the surface. For this purpose, we tested samples $\mathrm{C} 10 \mathrm{H} 2, \mathrm{C} 15 \mathrm{H} 2, \mathrm{C} 20 \mathrm{H} 2$ and a pristine sample at freezing temperatures of $-15{ }^{\circ} \mathrm{C},-20^{\circ} \mathrm{C}$ and $-25^{\circ} \mathrm{C}$. The freezing delay at $-5^{\circ} \mathrm{C}$ and $-10{ }^{\circ} \mathrm{C}$ was too long and, thus, was not considered for this experiment. Surfaces having micro-nanostructures froze later than the rubber surface lacking these structures (Fig. 11). Due to the micronanostructures, micro air pockets between the rubber surface and water droplets acted as thermal barriers to produce the freezing delay. Moreover, in the case of surfaces having a higher contact angle, the contact area between the water droplets and the rubber surface was less than that for 
pristine surfaces, meaning a decrease in thermal conductivity for the former. In other words, superhydrophobic surfaces dissipate less heat than pristine surfaces to produce a freezing delay [66].

The inset images in Fig. 11 represent the droplets at the moment of complete freezing for pristine silicone rubber and sample $\mathrm{C} 15 \mathrm{H} 2$ at $-25^{\circ} \mathrm{C}$. The small protrusion on the top of the frozen droplets is formed when the droplets are in a solid state. The lag time between freezing onset and solid state is short. At the onset of freezing, the white spot at the center of the liquid state water droplet disappears and the droplet becomes cloudy due to the crystallization nucleation [67]. As crystallization propagates, the solid-water interface line migrates from the bottom to top until the protrusion is created at the top of the droplet. The entire process takes less than $50 \mathrm{~s}$.

Sample $\mathrm{C} 15 \mathrm{H} 2$ was marked by the maximum WCA and had the longest freezing delay. Compared to pristine silicone rubber, it took $>3 \mathrm{x}$ longer for sample $\mathrm{C} 15 \mathrm{H} 2$ to freeze at $-25{ }^{\circ} \mathrm{C}$ and $-20{ }^{\circ} \mathrm{C}$. This difference relates to the more suitable surface roughness resulting in a smaller contact area between the rubber asperities and water droplets. 


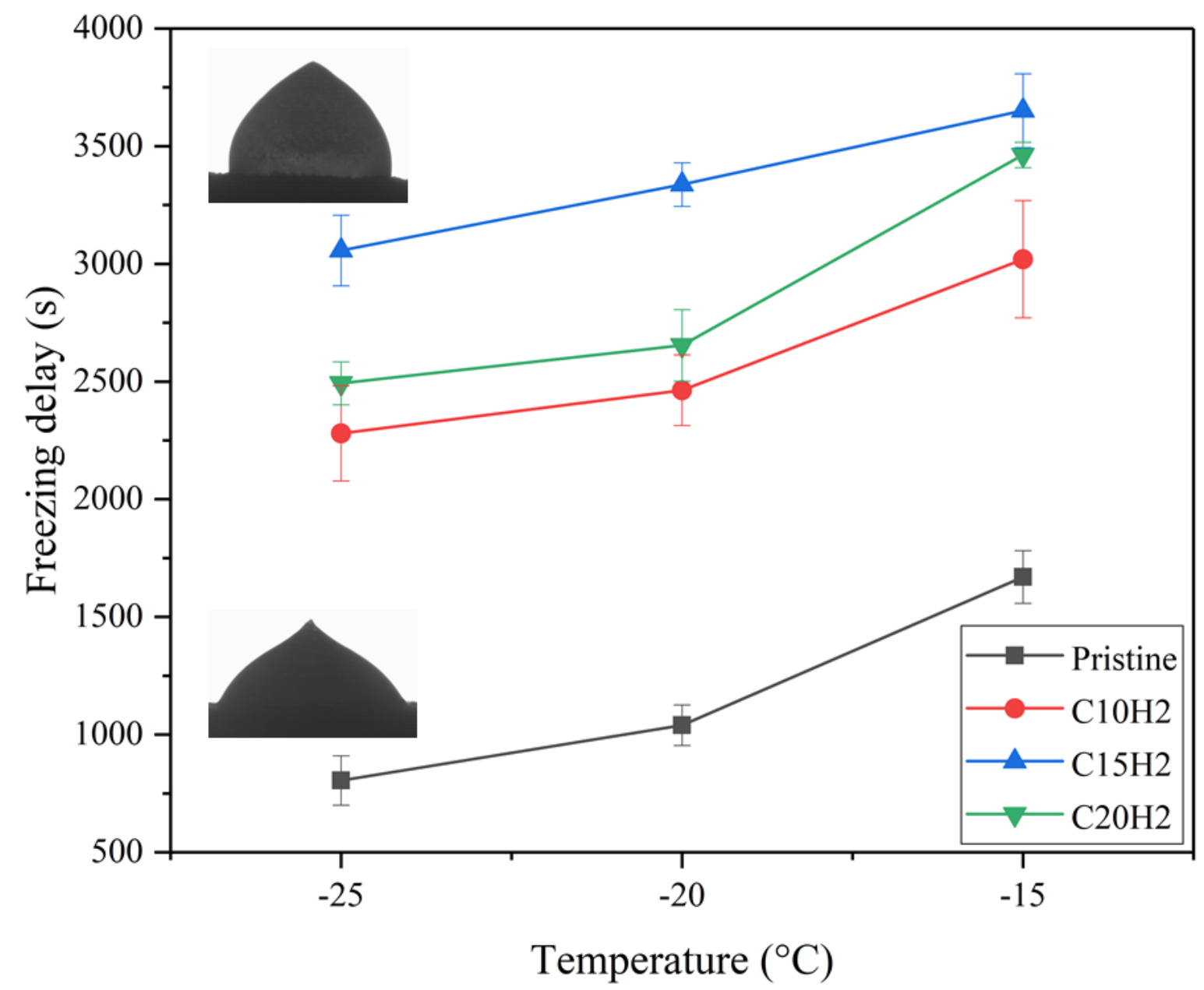

Fig. 11. Freezing delay of the silicone surface samples at various temperatures. Inset images represent the droplets at the moment of complete freezing for the pristine silicone rubber and sample $\mathrm{C} 15 \mathrm{H} 2$ at $-25^{\circ} \mathrm{C}$.

We studied the variations of static WCA at temperatures of $-25,-20,-15$ and $-10{ }^{\circ} \mathrm{C}$ for the different surfaces (Fig. 12). WCA decreased with the surface temperature. This reduction is expected as it is attributed to water surface tension at low temperatures [24].

Based on the literature, the decreased WCA for superhydrophobic samples should be greater than for the hydrophobic samples [65]. However, as temperatures decreased from $25{ }^{\circ} \mathrm{C}$ to $-25{ }^{\circ} \mathrm{C}$, the WCA of the pristine sample decreased $\sim 17 \%$ while decreasing by only $\sim 18 \%$ for sample $\mathrm{C} 15 \mathrm{H} 2$. Thus, although the micro-nanostructured samples showed superhydrophobic properties, these properties were altered at low temperatures as was the case for hydrophobic surfaces. However, the superhydrophobic surfaces still possessed a higher WCA than that of the pristine sample. 


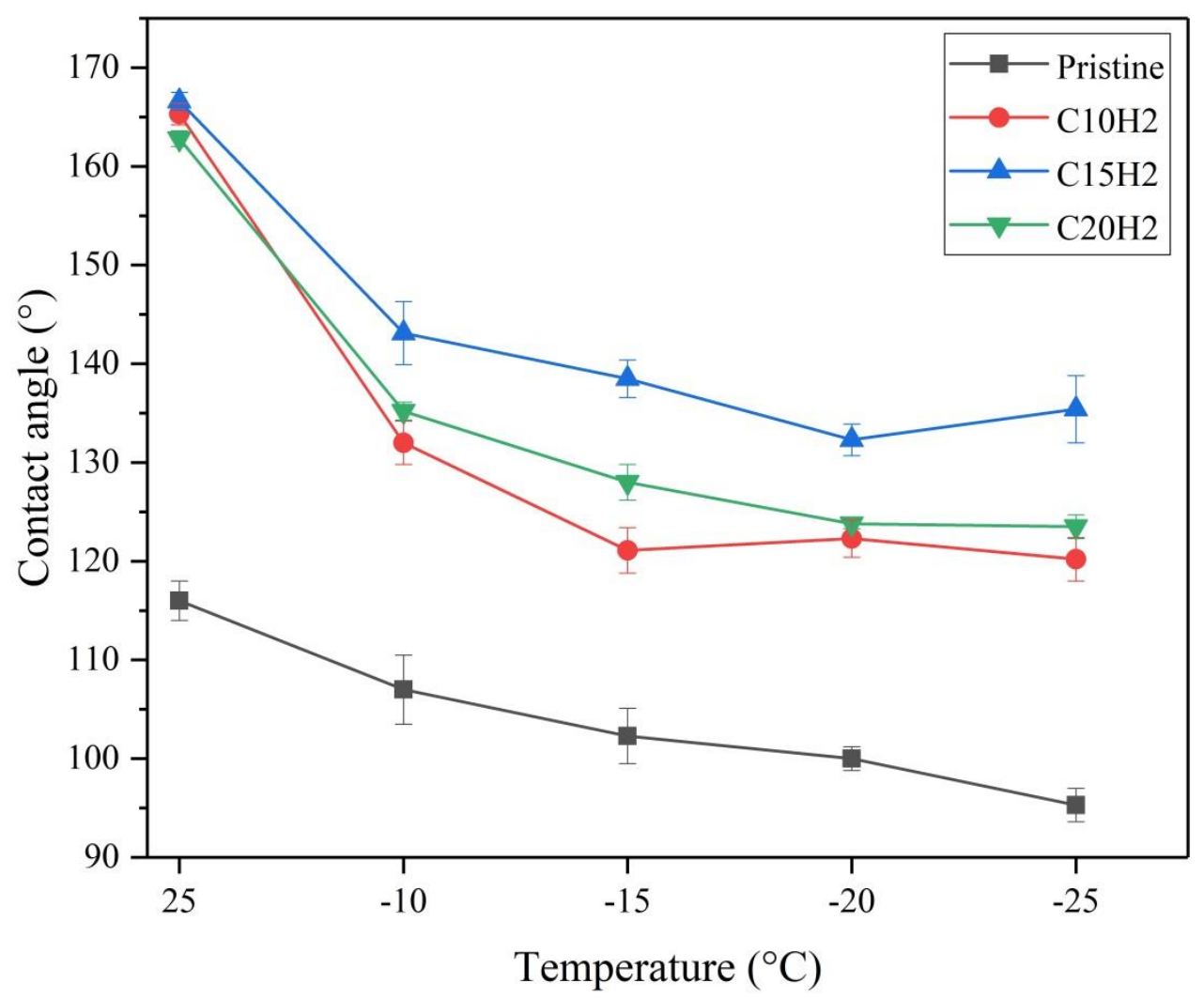

Fig. 12. Changes in static water contact angle at various temperatures for the different experimental silicone surfaces.

\section{Self-cleaning properties}

Self-cleaning is the ability of a surface to repel water droplets and remove dust particles adhered to the surface. As dust and pollution particles are generally hydrophilic, they easily adhere to water droplets rolling on a superhydrophobic surface, and they are removed as the droplets roll off the surface [68]. This behavior is due to the greater adhesion between water droplets and pollution particles than between pollution particles and a micro-nanostructured superhydrophobic surface [69]. Moreover, the very small contact area between the water droplet and the surface has a crucial effect in such behavior. For a certain type of surface, however, CAH is more important than static WCA for self-cleaning [70]. Therefore, a surface having a CAH $<10^{\circ}$ is generally referred to as a self-cleaning surface [70]. 
The self-cleaning property of the produced silicone surfaces was clearly observed when we compared the pristine and the produced silicone samples. When an equal amount of contaminants was added to the pristine (Fig. 13a) and C15H2 (Fig. 13b) samples, the cleaning route of a single water droplet on the latter surface (marked using red lines on Fig. 13) was clearly visible with the contamination removed by the water droplet (red circle in Fig. 13b). A $1.5 \times 2.5 \mathrm{~cm}$ area of the contaminated sample was self-cleaned using $\sim 4$ water droplets. Fabricated superhydrophobic silicone rubber surfaces having a $\mathrm{CAH}<3^{\circ}$ were self-cleaning; the pristine silicone rubber surface did not demonstrate this self-cleaning capacity as the water droplets simply accumulated on the contaminated surface (Fig. 13a).
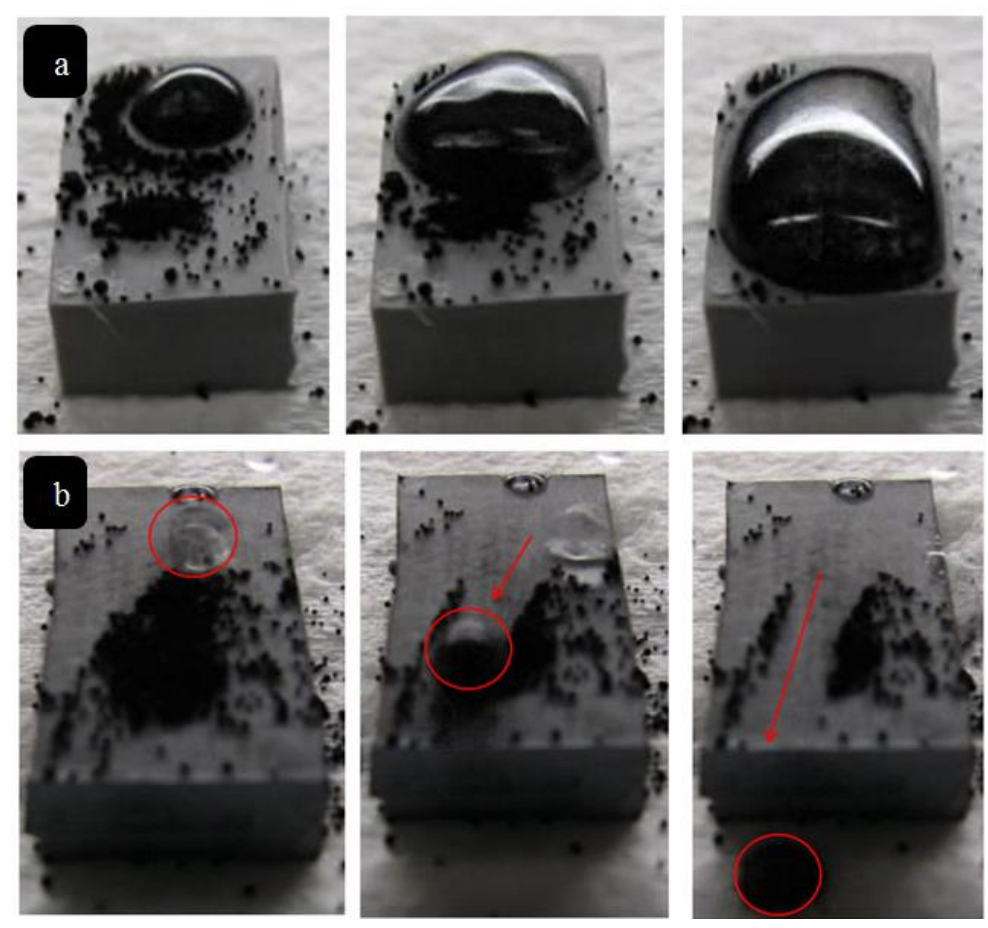

Fig. 13. Self-cleaning properties of (a) pristine and (b) superhydrophobic silicone rubber surfaces. Equal amounts of contaminants were added to the surfaces. The pristine surface shows an accumulation of water without removal of the contaminants. The superhydrophobic silicone causes water droplets to flow across the surface and pick up contaminants along the flow route (arrows in b). The removed contaminants are observed in the red circle in the third image for the superhydrophobic surface (b).

To demonstrate the remarkable ability of the superhydrophobic silicone surface to repel water, we placed the superhydrophobic sample into a Petri dish. Using a syringe and needle, we then added three red water droplets onto the prepared surface. Water was added to the Petri dish bringing the water level equal to the height of the sample. While it was expected that by pouring 
more water into the Petri dish, the sample would be completely immersed in water and the red droplets dissolved into the water mass, the superhydrophobic surface acted as a barrier against water thereby keeping itself dry (Fig. 14). Consequently, the red water droplets remained intact. To assess the longevity of this barrier, we kept the sample in the water container for more than one week. The sample remained dry during this period.

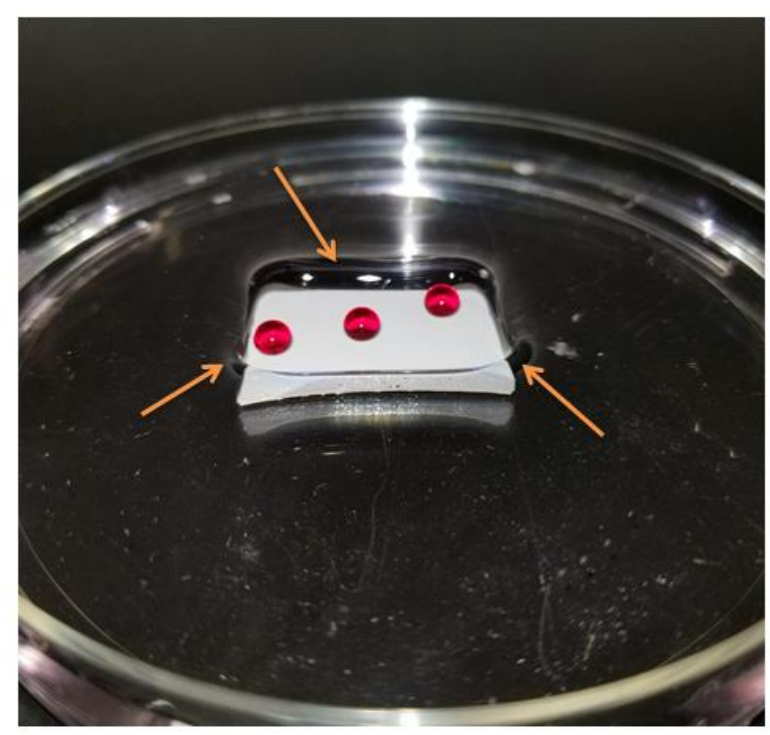

Fig. 14. A superhydrophobic silicone surface remaining dry while immersed in water. The red water droplets illustrate the separation of the surface from the surrounding water.

\section{Conclusion}

We developed a direct replication method for the manufacturing of micro-nanostructured superhydrophobic silicone surfaces. All samples produced under the various etching conditions displayed water contact angles $>160^{\circ}$ and contact angle hysteresis $<3^{\circ}$. Samples replicated from inserts produced with an acid concentration of $15 \mathrm{wt} \%$ demonstrated a slightly higher water repellency than samples produced from lower and higher acid concentration inserts. This higher water repellency was due to the relatively higher homogeneous surface roughness of the $15 \mathrm{wt} \%$ acid samples. SEM images confirmed the successful replication of the templates' patterns on the rubber samples produced via compression molding. The micro air pockets entrapped between the water droplets and the silicone surface (due to the surface roughness) were responsible for the observed superhydrophobic behavior. As demolding without damaging the replicate is a crucial factor in the processing of micro-nanostructured surfaces, we applied an antistiction coating, 
which contained fluorinated bonds, to the template surfaces prior to molding. FTIR analysis revealed that fluorinated bonds of the template surfaces did not transfer to the silicone rubber surfaces during the replication process. Remarkably, superhydrophobic samples delayed freezing onset confirming the icephobic capacity of the produced surfaces. The fabricated surfaces were also self-cleaning and easily removed introduced contaminants on the surface.

\section{Acknowledgments}

The authors acknowledge the financial support from the Natural Sciences and Engineering Research Council of Canada (NSERC) and K-Line Insulators Limited, Toronto, Canada. We also thank Filmetrics Inc. for carrying out the profilometry analysis, the Laboratory of Icephobic Coatings and Surface Engineering (LaRGIS) at the Université du Québec à Chicoutimi (UQAC) for providing the necessary equipment and materials for the experiments, and we thank $\mathrm{Mr}$. Pierre Camirand for his technical assistance and valuable help.

\section{References}

[1] G. Momen and M. Farzaneh, "Survey of micro/nano filler use to improve silicone rubber for outdoor insulators," Reviews on Advance Materilas Science, vol. 27, no. 1, pp. 1-13, 2011.

[2] Y. Gao, J. Wang, X. Liang, Z. Yan, Y. Liu, and Y. Cai, "Investigation on permeation properties of liquids into HTV silicone rubber materials," IEEE Transactions on Dielectrics and Electrical Insulation, vol. 21, no. 6, pp. 2428-2437, 2014.

[3] M. Amin, M. Akbar, and M. Salman, "Composite insulators and their aging: An overview," Science in China Series E: Technological Sciences, vol. 50, no. 6, pp. 697-713, 2007.

[4] Z. Yan, X. Liang, C. Wu, W. Bao, S. Li, and Y. Liu, "Aging and recovery of superhydrophobic silicone rubber under electrical and non-electrical stresses," In Electrical Insulation and Dielectric Phenomena (CEIDP), 2015 IEEE Conference on, 2015, pp. 189-192: IEEE.

[5] R. Jafari, S. Asadollahi, and M. Farzaneh, "Applications of plasma technology in development of superhydrophobic surfaces," Plasma Chemistry and Plasma Processing, vol. 33, no. 1, pp. 177200, 2013.

[6] M. Bhagyashree, K. Shivabasappa, S. Raavichandran, and S. Kumar, "Study of HTV silicone rubber with different concentrations of filler ATH," International Journal on Emerging Technologies, vol. 6, no. 2, p. 72, 2015.

[7] D. Bodas and C. Khan-Malek, "Formation of more stable hydrophilic surfaces of PDMS by plasma and chemical treatments," Microelectronic Engineering, vol. 83, no. 4-9, pp. 1277-1279, 2006.

[8] N. J. Shirtcliffe, G. McHale, M. I. Newton, G. Chabrol, and C. C. Perry, "Dual-Scale Roughness Produces Unusually Water-Repellent Surfaces," Advanced Materials, vol. 16, no. 21, pp. 19291932, 2004.

[9] H. Liao, A.-S. Andersson, D. Sutherland, S. Petronis, B. Kasemo, and P. Thomsen, "Response of rat osteoblast-like cells to microstructured model surfaces in vitro," Biomaterials, vol. 24, no. 4, pp. 649-654, 2003. 
[10] R. Jafari and M. Farzaneh, "Development a simple method to create the superhydrophobic composite coatings," Journal of Composite Materials, vol. 47, no. 25, pp. 3125-3129, 2013.

[11] E. Vazirinasab, R. Jafari, and G. Momen, "Application of superhydrophobic coatings as a corrosion barrier: A review," Surface and Coatings Technology, vol. 341, pp. 40-56, 2017.

[12] K. Maghsoudi, R. Jafari, G. Momen, and M. Farzaneh, "Micro-nanostructured polymer surfaces using injection molding: A review," Materials Today Communications, vol. 13, pp. 126-143, 2017.

[13] M. Zhang, S. Feng, L. Wang, and Y. Zheng, "Lotus effect in wetting and self-cleaning," Biotribology, vol. 5, pp. 31-43, 2016.

[14] X. Liu, W. Wu, X. Wang, Z. Luo, Y. Liang, and F. Zhou, "A replication strategy for complex micro/nanostructures with superhydrophobicity and superoleophobicity and high contrast adhesion," Soft Matter, vol. 5, no. 16, pp. 3097-3105, 2009.

[15] P. Zylka, "On the surface performance of superhydrophobic silicone rubber specimens fabricated by direct replica method," IEEE Transactions on Dielectrics and Electrical Insulation, vol. 21, no. 3, pp. 1183-1188, 2014.

[16] R. Liao, Z. Zuo, C. Guo, Y. Yuan, and A. Zhuang, "Fabrication of superhydrophobic surface on aluminum by continuous chemical etching and its anti-icing property," Applied Surface Science, vol. 317, pp. 701-709, 2014.

[17] D. K. Sarkar, M. Farzaneh, and R. W. Paynter, "Superhydrophobic properties of ultrathin rfsputtered Teflon films coated etched aluminum surfaces," Materials Letters, vol. 62, no. 8, pp. 1226-1229, 2008.

[18] R. Menini and M. Farzaneh, "Elaboration of $\mathrm{Al}_{2} \mathrm{O}_{3} /$ PTFE icephobic coatings for protecting aluminum surfaces," Surface and Coatings Technology, vol. 203, no. 14, pp. 1941-1946, 2009.

[19] Y. Liu, J. Liu, S. Li, Y. Wang, Z. Han, and L. Ren, "One-step method for fabrication of biomimetic superhydrophobic surface on aluminum alloy," Colloids and Surfaces A: Physicochemical and Engineering Aspects, vol. 466, pp. 125-131, 2015.

[20] S. Zheng, C. Li, Q. Fu, W. Hu, T. Xiang, Q. Wang, M. Du, X. Liu, and Z. Chen, "Development of stable superhydrophobic coatings on aluminum surface for corrosion-resistant, self-cleaning, and anti-icing applications," Materials \& Design, vol. 93, pp. 261-270, 2016.

[21] Y. Zhang, X. Yu, H. Wu, and J. Wu, "Facile fabrication of superhydrophobic nanostructures on aluminum foils with controlled-condensation and delayed-icing effects," Applied Surface Science, vol. 258, no. 20, pp. 8253-8257, 2012.

[22] R. Jafari and M. Farzaneh, "Fabrication of superhydrophobic nanostructured surface on aluminum alloy," Applied Physics A: Materials Science \& Processing, vol. 102, no. 1, pp. 195199, 2011.

[23] M. Vlaskin, E. Shkolnikov, and A. Bersh, "Oxidation kinetics of micron-sized aluminum powder in high-temperature boiling water," International Journal of Hydrogen Energy, vol. 36, no. 11, pp. 6484-6495, 2011.

[24] M. Rahimi, A. Afshari, and E. Thormann, "Effect of aluminum substrate surface modification on wettability and freezing delay of water droplet at subzero temperatures," ACS Applied Materials \& Interfaces, vol. 8, no. 17, pp. 11147-11153, 2016.

[25] R. Jafari, R. Menini, and M. Farzaneh, "Superhydrophobic and icephobic surfaces prepared by RF-sputtered polytetrafluoroethylene coatings," Applied Surface Science, vol. 257, no. 5, pp. 1540-1543, 2010.

[26] P. Hernández, A. Murawko, J. Martínez, G. Peláez, and E. Ares, "Replication of micro laser textures by injection molding," Procedia Engineering, vol. 63, pp. 885-894, 2013.

[27] B. K. Nayak and M. C. Gupta, "Self-organized micro/nano structures in metal surfaces by ultrafast laser irradiation," Optics and Lasers in Engineering, vol. 48, no. 10, pp. 940-949, 2010.

[28] R. Jagdheesh, J. García-Ballesteros, and J. Ocaña, "One-step fabrication of near superhydrophobic aluminum surface by nanosecond laser ablation," Applied Surface Science, vol. 374, pp. 2-11, 2016. 
[29] Z. J. Davis, G. Abadal, O. Hansen, X. Borise, N. Barniol, F. Perez-Murano, and A. Boisen, "AFM lithography of aluminum for fabrication of nanomechanical systems," Ultramicroscopy, vol. 97 , no. 1, pp. 467-472, 2003.

[30] C. Zhang, P. Yi, L. Peng, X. Lai, and J. Ni, "Fabrication of moth-eye nanostructure arrays using roll-to-roll UV-nanoimprint lithography with an anodic aluminum oxide mold," IEEE Transactions on Nanotechnology, vol. 14, no. 6, pp. 1127-1137, 2015.

[31] X. Wang, S. Xu, M. Cong, H. Li, Y. Gu, and W. Xu, "Hierarchical structural nanopore arrays fabricated by pre-patterning aluminum using nanosphere lithography," Small, vol. 8, no. 7, pp. 972-976, 2012.

[32] F. Wang, F. Lv, Y. Liu, C. Li, and Y. Lv, "Ice adhesion on different microstructure superhydrophobic aluminum surfaces," Journal of Adhesion Science and Technology, vol. 27, no. 1, pp. 58-67, 2013.

[33] Y. Zhang, D. Ge, and S. Yang, "Spray-coating of superhydrophobic aluminum alloys with enhanced mechanical robustness," Journal of Colloid and Interface science, vol. 423, pp. 101107, 2014.

[34] A. M. Escobar and N. Llorca-Isern, "Superhydrophobic coating deposited directly on aluminum," Applied Surface Science, vol. 305, pp. 774-782, 2014.

[35] A. B. Christiansen, J. S. Clausen, N. A. Mortensen, and A. Kristensen, "Injection moulding antireflective nanostructures," Microelectronic Engineering, vol. 121, pp. 47-50, 2014.

[36] A.-K. Holthusen, O. Riemer, J. Schmütz, and A. Meier, "Mold machining and injection molding of diffractive microstructures," Journal of Manufacturing Processes, vol. 26, pp. 290-294, 2017.

[37] M. Zhou, B. Jiang, C. Weng, and L. Zhang, "Experimental study on the replication quality of micro-nano cross-shaped structure arrays in injection molding," Microsystem Technologies, vol. 23, no. 4, pp. 983-989, 2017.

[38] K. Nagato, T. Hamaguchi, and M. Nakao, "Injection compression molding of high-aspect-ratio nanostructures," Journal of Vacuum Science \& Technology B, Nanotechnology and Microelectronics: Materials, Processing, Measurement, and Phenomena, vol. 29, no. 6, p. 06FG10, 2011.

[39] D. Masato, M. Sorgato, and G. Lucchetta, "Characterization of the micro injection-compression molding process for the replication of high aspect ratio micro-structured surfaces," Microsystem Technologies, vol. 23, no. 8, pp. 3661-3670, 2017.

[40] M. Rohde, A. Derdouri, and M. R. Kamal, "Micro replication by injection-compression molding," International Polymer Processing, vol. 24, no. 3, pp. 288-297, 2009.

[41] Y. Chen, Y. Y. Allen, D. Yao, F. Klocke, and G. Pongs, "A reflow process for glass microlens array fabrication by use of precision compression molding," Journal of Micromechanics and Microengineering, vol. 18, no. 5, p. 055022, 2008.

[42] S.-d. Moon, N. Lee, and S. Kang, "Fabrication of a microlens array using micro-compression molding with an electroformed mold insert," Journal of Micromechanics and Microengineering, vol. 13, no. 1, p. 98, 2002.

[43] D.-M. Chun, G. Davaasuren, C.-V. Ngo, C.-S. Kim, G.-Y. Lee, and S.-H. Ahn, "Fabrication of transparent superhydrophobic surface on thermoplastic polymer using laser beam machining and compression molding for mass production," CIRP Annals-Manufacturing Technology, vol. 63, no. 1, pp. 525-528, 2014.

[44] P. He, L. Li, F. Wang, O. Dambon, F. Klocke, K. M. Flores, and A. Y. Yi, "Bulk metallic glass mold for high volume fabrication of micro optics," Microsystem Technologies, vol. 22, no. 3, pp. 617-623, 2016.

[45] H. Becker and U. Heim, "Hot embossing as a method for the fabrication of polymer high aspect ratio structures," Sensors and Actuators A: Physical, vol. 83, no. 1, pp. 130-135, 2000.

[46] C.-J. Ting, M.-C. Huang, H.-Y. Tsai, C.-P. Chou, and C.-C. Fu, "Low cost fabrication of the large-area anti-reflection films from polymer by nanoimprint/hot-embossing technology," Nanotechnology, vol. 19, no. 20, p. 205301, 2008. 
[47] L. Peng, Y. Deng, P. Yi, and X. Lai, "Micro hot embossing of thermoplastic polymers: a review," Journal of Micromechanics and Microengineering, vol. 24, no. 1, p. 013001, 2013.

[48] J. Wang, P. Yi, Y. Deng, L. Peng, X. Lai, and J. Ni, "Recovery behavior of thermoplastic polymers in micro hot embossing process," Journal of Materials Processing Technology, vol. 243, pp. 205-216, 2017.

[49] C. J. Weng, C. H. Chang, C. W. Peng, S. W. Chen, J. M. Yeh, C. L. Hsu, and Y. Wei, "Advanced anticorrosive coatings prepared from the mimicked xanthosoma sagittifolium-leaf-like electroactive epoxy with synergistic effects of superhydrophobicity and redox catalytic capability," Chemistry of Materials, vol. 23, no. 8, pp. 2075-2083, 2011.

[50] S. D. Bhagat and M. C. Gupta, "Superhydrophobic microtextured polycarbonate surfaces," Surface and Coatings Technology, vol. 270, pp. 117-122, 2015.

[51] S. F. Toosi, S. Moradi, M. Ebrahimi, and S. G. Hatzikiriakos, "Microfabrication of polymeric surfaces with extreme wettability using hot embossing," Applied Surface Science, vol. 378, pp. 426-434, 2016.

[52] B. Y. Cao, Y. W. Li, R. Y. Dong, J. Kong, H. Chen, Y. Xu, and K. L. Yung, "Superhydrophobicity of self-organized surfaces of polymer nanowire arrays fabricated by a nano-injection moulding technique," Journal of Thermal Science and Technology, vol. 6, no. 2, pp. 204-209, 2011.

[53] T. Rasilainen, M. Suvanto, and T. A. Pakkanen, "Anisotropically microstructured and micro/nanostructured polypropylene surfaces," Surface Science, vol. 603, no. 14, pp. 2240-2247, 2009.

[54] E. Puukilainen, T. Rasilainen, M. Suvanto, and T. A. Pakkanen, "Superhydrophobic polyolefin surfaces: controlled micro-and nanostructures," Langmuir, vol. 23, no. 13, pp. 7263-7268, 2007.

[55] B. K. Nayak, P. O. Caffrey, C. R. Speck, and M. C. Gupta, "Superhydrophobic surfaces by replication of micro/nano-structures fabricated by ultrafast-laser-microtexturing," Applied Surface Science, vol. 266, pp. 27-32, 2013.

[56] S. Sarbada and Y. C. Shin, "Superhydrophobic contoured surfaces created on metal and polymer using a femtosecond laser," Applied Surface Science, vol. 405, pp. 465-475, 2017.

[57] C. Hopmann, C. Behmenburg, U. Recht, and K. Zeuner, "Injection molding of superhydrophobic liquid silicone rubber surfaces," Silicon, vol. 6, no. 1, pp. 35-43, 2014.

[58] F. Madidi, G. Momen, and M. Farzaneh, "Development of a stable $\mathrm{TiO}_{2}$ nanocomposite selfcleaning coating for outdoor applications," Advances in Materials Science and Engineering, vol. 2016, 2016.

[59] G. Momen and M. Farzaneh, "Simple process to fabricate a superhydrophobic coating," Micro \& Nano Letters, vol. 6, no. 6, pp. 405-407, 2011.

[60] S. A. Seyedmehdi, H. Zhang, and J. Zhu, "Superhydrophobic RTV silicone rubber insulator coatings," Applied Surface Science, vol. 258, no. 7, pp. 2972-2976, 2012.

[61] S. H. Yoon, N. G. Cha, J. S. Lee, J. G. Park, D. J. Carter, J. L. Mead, and C. M. F. Barry, "Effect of processing parameters, antistiction coatings, and polymer type when injection molding microfeatures," Polymer Engineering \& Science, vol. 50, no. 2, pp. 411-419, 2010.

[62] M. Matschuk, H. Bruus, and N. B. Larsen, "Nanostructures for all-polymer microfluidic systems," Microelectronic Engineering, vol. 87, no. 5, pp. 1379-1382, 2010.

[63] M. Matschuk and N. B. Larsen, "Injection molding of high aspect ratio sub-100 nm nanostructures," Journal of Micromechanics and Microengineering, vol. 23, no. 2, p. 025003, 2012.

[64] A. Cassie and S. Baxter, "Wettability of porous surfaces," Transactions of the Faraday society, vol. 40, pp. 546-551, 1944.

[65] G. Momen, M. Farzaneh, and R. Jafari, "Wettability behavior of RTV silicone rubber coated on nanostructured aluminium surface," Applied Surface Science, vol. 257, no. 15, pp. 6489-6493, 2011. 
[66] G. Heydari, E. Thormann, M. Järn, E. Tyrode, and P. M. Claesson, "Hydrophobic surfaces: topography effects on wetting by supercooled water and freezing delay," The Journal of Physical Chemistry C, vol. 117, no. 42, pp. 21752-21762, 2013.

[67] G. Heydari, "Toward Anti-icing and De-icing Surfaces: Effects of Surface Topography and Temperature," KTH Royal Institute of Technology, 2016.

[68] D. Wu et al., "Facile creation of hierarchical PDMS microstructures with extreme underwater superoleophobicity for anti-oil application in microfluidic channels," Lab on a Chip, vol. 11, no. 22, pp. 3873-3879, 2011.

[69] S. Liu et al., "Self-cleaning transparent superhydrophobic coatings through simple sol-gel processing of fluoroalkylsilane," Applied Surface Science, vol. 351, pp. 897-903, 2015.

[70] B. Bhushan, "Biomimetics: lessons from nature-an overview," éd: The Royal Society, 2009. 